\title{
Salinization and freshening processes as additional factors for mobilization of geogenic contaminants: Evidence from boron isotopes in groundwater from northwestern India
}

\author{
R.M. COYTE ${ }^{1}$, D. DAS ${ }^{2}$, R. BALA ${ }^{2}$, R. JAIN ${ }^{3}$, A. \\ VENGOSH $^{1}$
}

${ }^{1}$ Division of Earth and Ocean Sciences, Nicholas School of the Environment, Duke University, Durham, NC 27708 (*correspondence: rmc33@duke.edu)

2 Department of Geology, Panjab University, Chandigarh, India

${ }^{3}$ Former Chairman, CGWB and CGWA, Ministry of Jal Shakti, Government of India

Groundwater is a diminishing commodity in India because of climate change and the over-extraction of water resources. The degradation of water quality poses additional risks to human health and food security. Alluvial aquifers, some of the most important and exploited aquifers in India, suffer from severe quality issues related to both human health $\left(\mathrm{U}, \mathrm{NO}_{3}^{-}, \mathrm{F}^{-}\right)$and agriculture $(\mathrm{B}$, salinity). Water quality in these aquifers is affected by anthropogenic contamination, water-rock interactions, and evapotranspiration, resulting in salinization. Massive irrigation and seasonal monsoon recharge results in the mixing of salinized groundwater with lower saline recharge water. Using geochemical data collected from 309 wells in Gujarat, Rajasthan, and Punjab in Northwestern India, we show systematic enrichment of $\mathrm{Na}$ as a result of reverse cation-exchange in shallow low-saline groundwater from the northern and more shallow aquifers, which receive more recharge, while more saline and deeper groundwater from southern aquifers show relative $\mathrm{Na}$ depletion. Variations in boron isotopes support this, with low $\delta^{11} \mathrm{~B}(\sim 0 \%)$ and high $\mathrm{B} / \mathrm{Cl}$ ratios in the low-saline groundwater and high $\delta^{11} \mathrm{~B}$ $(\sim 30 \%)$ and low $\mathrm{B} / \mathrm{Cl}$ in the saline groundwater, reflecting desorption and adsorption processes, respectively. These reactions are important to controlling groundwater chemistry and have implications for the occurrence of geogenic contaminants, such as $\mathrm{F}^{-}$and $\mathrm{U}$ in groundwater. $\mathrm{As} \mathrm{Ca}^{2+}$ concentrations decrease during reverse base-exchange reactions, saturation indices for fluorite and calcite decrease, leading to $\mathrm{h}$ of $\mathrm{F}^{-}$and $\mathrm{HCO}_{3}{ }^{-}$(related to $\mathrm{U}$ solubility) in the groundwater. At the same time, freshening is a dilution process, which in some cases keeps absolute concentrations of these contaminants low. 